Journal of Teacher Education for Sustainability, vol. 8, 2007, pp. 37-47

\title{
ARE TEACHERS TIRED OF RESPONSIBILITIES?
}

\author{
Mare Tuisk \\ Tallinn University, Estonia
}

\begin{abstract}
Estonian educational life is at a crossroad. Schools and their educational functions have become the focus of public discussion because of the worrisome tendencies in childhood and adolescent life (dropping out of school, deteriorating mental and physical health, increase in self-destructive behaviour, etc.). Many teachers are overtaken by tiredness and apathy. To the amazement of colleagues, even the best teachers are suffering from burnout and leaving school. What are the reasons for these phenomena?

The general context of this article is the problem of sustainability in education and, consequently, the sustainability of society. This paper focuses on how teachers perceive themselves as subjects and how they can promote learners' becoming subjects and is based on 48 narrative essays. The author has interpreted the outcomes relying on the works of A. Maslow, L. Vygotsky, V.Peavy, and M.Fullan.

The most significant conclusion is that there is a contradiction between the teachers' strong feeling of mission and responsibility which contrasts with the diminishing possibilities of implementing these priorities in their real work. Teachers assume they are accepted as decisive and responsible professionals. Furthermore, they expect other participants of educational processes to share responsibility.
\end{abstract}

Key words: teachers; being a subject; responsibility; co-operation; attitudes; sustainable development.

Guidelines and Recommendations for Reorienting Teacher Education to Address Sustainability (2005) starts with a reference to Agenda 21, Chapter 36, which says, that education alone will not move citizens and governments to create a more sustainable future. However, the next extract states: "Education is essential for moving toward a more sustainable future" (Guidelines..., 2005). Education alone cannot manage everything, but without education nothing can be managed. Education plays a key role in change.

\section{Background}

In Estonia, we have lived in a democratic society for some time now. Fundamental reorganisations have resulted in major improvements, but have also caused post-industrial strains and problems: "Contemporary society exploits formulas, which require effectiveness, speed and maximum achievements with minimum effort, which result in 
stressful life" (Peavy, 2002:15). Unfortunately, the societal problems are also reflected at school, affecting the learning environment and teacher-student relations.

The attempt to interpret school life is based on two approaches, which share a common ground, but have different perspectives. The socio-cultural approach relies on an individual or group's cultural background and social relations while participating in human activities. The most eminent representative of this approach, L.Vygotsky, has declared: "Human's education is fully determined by social environment he grows and develops in" (Vygotsky, 2000: 199). Socialization helps children acquire the standards and norms of a particular society. Socialization introduces the child to her/his historically developed culture and personal cognitive system of meanings and values. Since the social and cultural conditioning of education has a temporal dimension, the impact of significant social changes of the last decades in Estonia must be considered. The socio-cultural approach is definitely applicable from the aspect of sustainable co-existence of society and the school.

The new trends in socio-dynamic approach represented by V.Peavy's ideology of counselling have concentrated on supporting an individual's subjective existence, however, it emphasizes that "problems are usually not in thinking or personal characteristics, but in the context and human relations" (Peavy, 2002: 23). Furthermore, Peavy adds that "human life is linguistic life and socio-dynamic counselling is "wordplay" (ibid.: 10). Hence, we are back in socio-cultural domains. In an educational setting, the socio-cultural approach helps to analyse the situation, its causes and dynamics. The socio-dynamic approach concentrates on how to interpret the surrounding environment and cope with it as a subject.

A.Maslow's theory of needs (Maslow, 2002) is relevant to when considering the personality of students. In an educational context, it is necessary to emphasize the importance of fulfilling belonging, esteem and self-actualization needs.

Moreover, Maslow claims that "self-actualization is not the moment when we reach total bliss, but an intense process of continuous growth, a grievous task of collecting small accomplishments" (Maslow, 2002: 62). Analysing the background of emotions, motivation and activities, we should always consider the needs of humans. Even if teacher begins to doubt his or her work satisfaction or life in general, Maslow's theory provides a secure basis for mapping the situation and seeking solutions.

The self-actualization of teachers is treated in the following generalization: "Teachers have no opportunity to delve into problems... If one is compelled to act in the name of abstract and controversial aims, it leads to bewilderment and frustration, and eventually quitting the endeavours" (Fullan, 2006: 29). There is surely food for thought for professionals studying the current educational situation in Estonia. Estonia's transitional society is in a phase of searching for answers. However, the direction education should take still lacks a consensus. Unfortunately, life does not wait for anyone and people must find a philosophy that gives meaning and direction to their lives. The basic issue in philosophy is being a subject and this position also determines whether teachers will treat their students as subjects of self-development or objects to be manipulated by teachers. One of the most crucial steps in pedagogy is actually implementing the philosophy of dialogue between the equal subjects, which requires major changes in school culture and management. The phenomenon of dialogic communication is still to be interpreted on the level of teachers and organisations. There is an essential difference between when the person is an object of manipulation or when he/she is an acceptable partner. It is not only world play, but also the central idea of discourse. 


\section{Research method and procedures}

Since in hermeneutics, especially in a socio-dynamic context "... human beings are, first and foremost, "story-tellers", "renderers of meaning" and collectively active "creators of the world" (Peavy, 2002: 21), the research method chosen was analysis of narrative essays based on the method of grounded theory.

The research involved 25 elementary education students participating in the elective study course "Being a Subject in Education". The majority of the participants were class teachers (grades 1-6). Their professional teaching experience ranged from five months to 18 years, from small rural schools to big urban schools. Essay writing on the topics of "Supporting a Student's Development as a Subject" and "Teacher as a Subject in Contemporary Estonian School" was their writing assignments. Before assigning the topics, teachers were told that the writing is an exercise in self-reflection and that they would not be evaluated assigning marks to their essays.

The thematic utterances or extracts carrying the underlying idea of the research were numbered and coded on the first reading. Secondly, axial coding took place and, finally, selective coding was used (Strauss \& Corbin, 1998). The article concentrates on the results of axial coding, which are represented by the categories of changed family education, teacher responsibility, characteristics of professional teacher, and a teacher as a subject. Summative statements and behavioural patterns are illustrated by teachers' quotations and followed by brackets where the first number stands for the teacher code and the number after the forward slash for the sequence number of the utterance in a particular essay.

The objective of the current research is to provide an overview of teacher opinions about the subjective self-realization in contemporary Estonia. Hence, responses to the following questions are expected:

- What changes have occurred in the social system concerning education and teacher roles?

- What factors obstruct the teachers' self-actualisation as subjects?

- Which positive developments and solutions are the teachers aware of?

\section{Results}

Before analysing the research results, it should be noted that the essays were written by professional teachers who are finishing their speciality studies at the university. Such a symbiosis presupposes that the opinions expressed in the essays are based on both practical experience and freshly acquired theoretical knowledge, which might explain the expressed sensitive criticism when expectations and school reality do not coincide. Moreover, this shows potential for more conscious analysis and motivation necessary for changes. Interpreting the background, it is pleasant to see the wide perspective of teachers, which is also characterised by the first collective category.

\section{Broken childhood}

The majority of teachers express a confident belief that early childhood experiences play a crucial role in the child's development and this depends mainly on parents. As a house cannot choose its builder, a child cannot choose his parents (T1/5). Furthermore, 
parents cannot always choose the developmental environment suitable for children. Essays exemplify numerous shortcomings in early childhood, such as:

Development requires possibilities of play and other activities. Without it the child cannot be put on a test, be active or creative (T14/18). A child should have a chance of taking roles, setting aims .... but how to put it into practice, if the child's own spaces have disappeared - bus stops and gasoline stations have become their meeting places. Children have become consumers, almost everything is ready-made... Even the aims of children's activities are no longer their own and the ones offered by parents are often not accepted (T18/3, 24, 25).

Upon analysing teacher opinions, a certain pattern of childhood prevails, where the horizon remains limited, both initiative and creativity are inhibited and a consumer mentality predominates. Maslow (1970) claims that children create themselves. However, this presupposes an inspiring environment and a child's activity. Childhood as a socio-cultural phenomenon starts at home and from its surroundings, and the effects of its impairment are visible at school. The teachers describe the need to encourage pupils to concentrate on and research things, and therefore, the current category also included the sub-categories of children's laziness of mind, which were continuously illustrated in the essays with the pupils spontaneous reaction: "I cannot be bothered". The resounding idea is teacher helplessness, since the causes of these factors cannot be altered and the outcomes of these unfavourable effects should be dealt with to a greater degree.

Another problem is parents. On the one hand, high expectations of home education are described, for example:

Home is a place where somebody awaits and cares for you; there are specific house rules.... cultural values and norms as the obvious rules of life are acquired there... strength is gathered at home (T15/17-19).

However, the reality is:

Many parents have to admit that they know nothing about their children's doings and problems. It is claimed that they have everything - nice clothes, a clean home, and pocket money. But children are left alone with their troubles (T2/42, 43).

Hence, the teacher acknowledges:

School has been called the second home of the child. For some, even the first, since the home does not fulfil its tasks. If the parents cannot be responsible, the school must be (T11/15).

Self-sacrificial solutions to different problems have been described, e.g.:

If nobody has time at home and mother does half of the child's homework in order to get it over with, the teacher must work with the child after lessons (T11/37).

Since home education is shattered and many things are wrong at such an early age, we can only rely on miracles at school. Such an emphasis is so dominant in different variations that it reminds us of a desperate defence reaction against all public declarations that accuse schools. 
Concentrating on the analysis of parent-children relations from a socio-cultural perspective, we see that teacher expectations concerning parents are mostly connected to forming an understanding of values and behavioural norms. Unfortunately, the teachers stress that the children have been left alone, hence, the family's socializing role has been transferred to the teacher. The same conclusion can also be reached analysing the circumstances from a socio-dynamic aspect, as teachers describe situations where homes cannot even satisfy the needs of security and belonging. Children are not listened to, understood or supported; hence, they seek teacher attention. Teachers comprehend the pupils' needs; however, these are hard to meet in over-sized classes and the inability to attend to student needs may contribute to teacher burnout.

\section{Burden of responsibility accompanying the role of class teacher}

Because the classroom teacher is the first and often the only teacher a child has interaction with at the beginning of her/his school experience, the teacher is in a unique position and responsibility, which cannot be shared by anybody. An experienced teacher writes:

As a class teacher I have an obligation and responsibility to form basis for the children's knowledge and world view and develop their self-image. I have become their second mother, trustee, counsellor and supporter... and this continues for half a page! (T23/7-16).

The categories dominating teachers' domain of responsibility were the following: information selection, independent thinking, self-analysis, setting goals, creativity, social skills, initiative, expression of interests and abilities, providing encouraging feedback, integrating different activities, etc. The teacher essays indicate important changes in emphasis, because the content of education and its basic values are socio-cultural phenomena. For decades the primary aim of education has been to provide knowledge often presented in authoritative manner. Today, however, teachers face the responsibility of developing the learner's self-image, social skills, skills of seeking and selecting information, etc. The essays reflect a contradiction between the declared tendencies and real situation:

Estonian school is knowledge centred and developmental sides are left undeveloped (T14/29). We measure everybody with the same criteria, compare schools and classes, pupils and teachers, tests and national exams everything and everybody! (T14/39).

Paradoxically:

The teacher is held responsible for pupils passing their tests and exams. Not the child or the parent (T20/25).

Teachers see a contradiction between the subject-centred "point hunt" and the primary goal of education:

Contemporary schools cannot manage with mere "subject specialists". Teachers do not teach a subject or class, but individuals, and besides being a teacher shelhe is also an educator (T19/15). 
Unfortunately the educational aspirations are sacrificed to economics:

Every child embodies reflections of past and present and potentials of $\mathrm{fu}$ ture. To understand it we must delve into her/his hidden nature... (T2/32).

A young male teacher describes:

If there are 35-36 pupils in the class, one cannot notice nor respond to their worries and joys (T10/3).

The essays reveal that the expectations towards teachers by school authorities and parents have broadened and changed within the educational situation. Responsibility can be taken for what you have chosen and decided on. However, the teacher is facing an unethical choice: on the one hand, she/he is responsible for currently valued personal development, social skills, etc. But in reality, schools and parents expect higher marks on state tests. Time sets limitations, curriculum is oversized and everything cannot be achieved at once. Such a schizophrenic splitting may cause burnout among conscientious teachers.

The essays of researched teachers reveal that they sense their mission and responsibility, however, the burden is too heavy to be carried alone. They consider it unfair that besides their primary mission, they only have duties and responsibilities, and the other parties have only expectations and rights. The teachers' behavioural pattern reminds one of a heroic soldier whose rear is weak and energy reserves ending. Surrendering, however, is not an option. When we speak about the category of responsibility on the theoretical level, we can apply both socio-cultural and socio-dynamic approaches. Based on the analysed essays by teachers, a society that mostly values external success, which is measured in numbers (e.g. results on state exams, amounts earned, etc.), may not be sustainable for a long time. When teachers, but also students are forced to operate in such conditions, they cannot develop. Socio-dynamic approaches stress that one should not concentrate on what is wrong, missing, or impossible, but on a constructive present, “...which includes existential realities with future possibilities, casting aside a perception of oneself as a helpless creature. .... the Socio-dynamic approach is empowering" (Peavy, 2002: 16). School as a social environment depends greatly on the teacher's personal mind and energy resources.

\section{Contemporary problems related to being a teacher}

Teachers understand that personal coping abilities have become essential in changing circumstances:

In present-day schools where children are very self-assured and parents demanding, the teacher must be a strong personality (T19/22, 23).

The category of purposefulness was considered essential in the majority of essays. Moreover, the importance of values related to self-image was also stressed, especially in connection to choices and decision-making. Discussions about priorities were also included in the value category. For example:

Daily decision-making has lately become more connected to planning the sequence of activities. Hence, school activities take priority and home affairs are cast aside $(\mathrm{T} 9 / 5,6)$. 
The frequent use of the expression "courage of decision-making" is especially noteworthy. For example:

There are teachers, who work as oiled tools, even against their principles... There are also teachers, who are sincere, wise, and bold. I have seen them cry, but they have remained faithful to themselves (T13/2, 5).

Another category, which was frequently mentioned in relation to decision-making, was the harmony of words and actions.

Moreover, the skills of self-analysis were regarded as crucial:

If a person has self-critical thinking, she/he can take time out and look into her/himself or even observe her/himself from aside. In a difficult situation one should find its starting point and untie the problem, find the reasons, seek help from elsewhere, but not to surrender (T11/33, 34).

A novice teacher writes:

I recall a proverb - one learns from mistakes. I would say - one learns from experience (T13/26).

The category evident in a majority of essays was developmental need, which was predominantly associated with in-service training, although not exclusively so. Novice teachers see possibilities in daily work as well:

I consider myself lucky for living in this time of change because there is so much to learn from different people and situations. Why not to learn from children and their parents? (T13/11).

Furthermore, the category of the ability to exert oneself was strongly represented. A young mother describes it rather colourfully:

On numerous weekends, holidays and weekday evenings I am with my family, although actually I am not, i.e. "there is a picture, but there is no sound", a mother must not be disturbed. As if a hurricane has run over me, and all because of my choice to become a teacher (T1/29).

Matching role-derived high expectations and strains pertaining to personal wishes, convictions and energy resources is a difficult task in contemporary schools, which is illustrated by the widespread indication of teacher burnout in the studied essays. The wisdom of an experienced teacher is reflected in the following opinion:

If work becomes an obsession for a teacher, the danger of burnout becomes a reality and we no longer can speak about effective teaching. A good teacher knows when and how to work and rest. She knows her value and by looking after herself, she also looks after the others, both at work and in her private life (T4/33-35).

The teachers' essays also reveal concern about authoritarianism. Although the need for understanding and good relations, and respect for mental freedom is emphasized, the problem of forcing oneself or the textbook wisdom on pupils is more dominant. A novice teacher expresses: 
If the teacher gives orders and makes decisions, the child is merely a subordinate. The teacher is the person solely responsible for the outcomes. My primary idea is to study together, help the pupils to learn, explore, experience new things, at the same time, teach as little as possible! However, this is achievable only if we are partners with pupils (T4/8-10).

The principle of partnership is recurrently mentioned, unfortunately with regret:

But it does not work. Maybe the reason is in historic background ("Child talks when the hen pees" and other similar proverbs),... or an authoritarian adult does not want to confess her weaknesses and mistakes (T13/25, 26).

At the same time we read that the problem is not in confessing one's mistakes but in attitudes:

What kind of a person can I mould with my example and value appraisals (T17/25).

Unfortunately this opinion exemplifies the paradigm of a dominating teacher, where child has to take the role of a manipulated object. However, alternative ideas expressed in the following extracts are encouraging:

Teacher is the creator of conditions. If the teacher creates an environment, which is developing, secure, stimulating and motivating, she/he supports the development of a pupil as a subject (T4/14). We, the adults, should learn to trust the children, support and acknowledge their choices (T17/21).

\section{Teacher's self-actualisation as a subject}

Teachers can be divided into different and even contradicting groups depending on their opinions about being a subject. Although being a subject is thought to be a natural prerequisite of teaching, it is still stated that teachers feel powerless facing many external requirements and expectations. An experienced teacher summarises:

Being a teacher, I must show initiative in preparing and conducting lessons, however, everything I have to do is dictated by authorities. Syllabi have to be completed and standard-determining tests have to be passed. Hence, the work must be strictly regulated and routine (T5/15-16).

The effect of authoritarianism has also been mentioned in the essays. An experienced teacher describes the situation as lacking perspective and words a striking strategy of self-realization:

If the teacher has always obeyed the orders and never sought explanations, she becomes a commander and the pupil a subordinate, who is not allowed to think, act, nor be responsible for outcomes... To encourage students to become subjects, teachers have to be subjects themselves and I believe encouraging students as subjects in such a school is dummy education! (T16) 9, 10). 
A novice teacher writes:

I belong to the indigo generation, who does not obey for obeying, but who perceives the world differently and is able to think and act independently. I am driven by selfishness and naivety. It is easy to follow a much-used path, but more difficult and rewarding to find one's own path (T9/22, 25).

Furthermore, teachers included the category of developmental need in their essays:

Coping with oneself is a continuous process, which makes us act and seek feedback: how to manage with the surroundings, what I have done wrong and what can be changed (T2/5, 6).

However, feedback is often lacking:

I go to work but what I do there interests nobody! Everything is wonderful if children are quiet, home assignments are in e-school on time and treated topics correspond to syllabus! Numerous papers must be filled in, however, their content should also interest somebody! (T16/15-17).

Moreover, teachers' subjective activities require collegial co-operation, which would deepen their belief in the fairness of the actions, their solidarity and sense of security. The category of co-operation is connected to school as an organisation:

The dominant mentality at school depends on its culture; whether one can talk about problems and whether these are constructively solved. Co-operation always offers better possibilities, however good a person is at her/his job... Criticism and tolerating it, asking for and offering help is also collaboration - co-operation is extremely valuable for teachers (T19, 14, 29, 30).

Why do teachers write about the need for collaboration and not about positive cooperative experiences? Theory stresses: "The so called "classroom strains" draw teachers' attention to daily or short-term activities, exhaust their energy resources and limit the possibilities to contemplate on their activities" (Fullan, 2006: 24). "The multi-dimensional aspect of change is not perceived. Changes in objectives, behaviour, philosophy etc are on stake" (ibid.: 7). The author's research indicates that teachers consider their work to be strenuous and understand that the habit of relying on former individualistic experiences is no longer sustainable.

To generalise, the school reality assessed by the teachers has mainly remained authoritarian, despite the endeavours of making society and education more democratic. The socio-cultural approach interprets it as an identity crisis. The necessity for a subject who thinks, makes decisions, and acts according to one's convictions is inevitable, however, in a school context it can be hard to achieve. Collegial co-operation and contemporary organisational culture are needed to achieve the necessary changes.

\section{Conclusion}

The social background of a teacher's work has considerably changed. Teachers sense the high expectations, responsibility, and pressure on their ability to cope. However, the possibilities of successful fulfilment of their mission seem to be gradually fading, especially if the current social system and subject-object paradigm in education pre- 
vails. The mere transfer of knowledge demanded by the curriculum into the learner's head, which would guarantee success in standard-determining tests and state exams, is no longer sustainable.

Teachers, who take the responsibility for the welfare of children and schools, cannot manage any more. Besides conscientiousness and dedication, burnout and alienation are described. Teacher solitude and tiredness of facing requirements that cannot be responded to in the contemporary school context are the resounding themes of the essays. However, this does not satisfy the teachers with a sense of mission - in reality, meaningful objectives and solutions are looked for.

The essays reflect a clear need for the attention of colleagues and authorities, for feedback, and acknowledgement. Teachers expect to be respected as subjects with independent thinking, decision-making, and sense of responsibility. Moreover, they expect other parties, parents and school authorities, to take responsibility for the aspects that depend on them. Teachers think that the anticipated results could be achieved through meaningful, supportive, and encouraging collaboration. Some problems highlighted by the teachers require changes of the state's educational policy, since the current reforms (curricula, organisation of state exams) have proven to be too short-term and not sustainable.

Agenda 21 stresses: "The core themes of education for sustainability include lifelong learning, interdisciplinary education, partnerships, multicultural education and empowerment. Special attention should also be paid to the training of teachers, youth leaders and other educators" (Guidelines...2005: 15).

The teacher essays give ample food for thought concerning teacher training, where besides general subjects and didactics, more attention ought to be paid to teachers' personal coping abilities, starting from the teacher's personal educational philosophy and finishing with copying with burnout. Training school leaders, especially in the matters related to organisational behaviour, introducing and implementing successful personnel administration, is another priority.

The lack of sustainability in education is expensive. Consequently, changes in the educational sphere are inevitable. Fortunately research results indicate that despite the tiring sense of responsibility, teachers have maintained their creativity and curiosity. Pupils, teachers, as well as all of society deserve better future.

\section{References:}

Fullan, M. (2006) Uudne arusaam haridusmuutustest [New approach to educational changes]. Tallinn: Atlex.

Guidelines and Recommendations for Reorienting Teacher Education to Address Sustainability (2005) Education for Sustainable Development in Action, Technical Paper No. 2 UNESCO Education Sector.

Maslow, A.H. (1970) Motivation and Personality (2 ${ }^{\text {nd }}$ ed.). New York: Harper \& Row Publishers.

Peavy, V.R. (2002) Sotsiodünaamiline nõustamine [Sociodynamic counselling]. Tallinn: Eesti Tööhõiveamet.

Strauss, A. \& Corbin, J. (1998) Basics of Qualitative Research Techniques and Procedures for Developing Grounded Theory (2nd ed.). London, Thousand Oaks, New Dehli: Sage Publications. 
Выготский, Л.С. (2000) Психология [Psychology]. Москва: Эксмо Пресс.

Маслоу, А.Г. (2002) Дальние пределы человеческой психики [Further limits of human psyche]. Санкт-Петербург: Евразия.

\section{Correspondence:}

Mare Tuisk, MA, Faculty of Educational Sciences, Tallinn University, Narva mnt 25, Tallinn 10120, Estonia. Email: maretuis@tlu.ee

Received 2 February, 2007; revised version received 25 October, 2007 